\title{
Formação para marisqueiras em segurança de alimentos e saúde do trabalhador: uma experiência na comunidade de Ilha do Paty, Bahia, Brasil
}

\author{
Training for female shellfish gatherers on food safety and worker's \\ health: an experience in the community of Ilha do Paty, Brazil
}

Gabriela Silva da Nóbrega ${ }^{1}$

Ryzia de Cassia Vieira Cardoso ${ }^{2}$

Dalva Maria da Nóbrega Furtunato ${ }^{2}$

José Ângelo Wenceslau Góes ${ }^{2}$

Tereza Cristina Braga Ferreira ${ }^{2}$

Mary Daiane Fontes Santos ${ }^{3}$

Sissa Maria Garrido Santos ${ }^{4}$

${ }^{1}$ Grupo de Pesquisa em Segurança Alimentar e Comércio Informal de Alimentos (Sacia), PósGraduação em Alimentos, Nutrição e Saúde, Escola de Nutrição, Universidade Federal da Bahia (UFBA). R. Araújo Pinho 32, Canela. 40.110-150 Salvador Bahia Brasil. gabrielasnobrega@ hotmail.com

${ }^{2}$ Departamento de Ciência dos Alimentos, Escola de Nutrição, UFBA.

${ }^{3}$ Programa de PósGraduação em Ciência de Alimentos (PGALI), Faculdade de Farmácia, UFBA.

${ }^{4}$ Medicina Veterinária, UFBA.
Abstract This study describes an experience in the training of female shellfish gatherers in the fishing community in Ilha do Paty, São Francisco do Conde, within the context of actions to promote health and food safety. This is an intervention study with planning of activities by a multidisciplinary team. The activities were developed in five stages: survey of topics of interest; awareness; female shellfish gatherers' work routine; teaching of best practices in the processing of shellfish; and group conversation. The methodologies included exposure through dialogue, group $d y$ namics, workshops, theater, work with images, directed activities and the distribution of educational materials. At the end, an evaluation by the participants regarding the different aspects was conducted. Overall there was satisfaction among the audience for most indicators, which may relate to both the use of audiovisual resources and strategies that permitted the exchange of experiences regarding the recognition of the importance of training by the target audience. The experiment demonstrates the potential of developing educational activities with the fishing communities, with results that contribute to the bolstering of the local supply chain, with the promotion of food safety and occupational health.

Key words Small-scale fishing, Seafood, Health education, Training, Occupational health, Food security
Resumo Este estudo objetiva descrever uma experiência de formação para marisqueiras, conduzida junto à comunidade pesqueira de Ilha do Paty, São Francisco do Conde, em um contexto de ações para promoção da saúde e da segurança alimentar. Estudo de intervenção, com planejamento de atividades por equipe multidisciplinar. As atividades foram desenvolvidas em cinco etapas: sondagem de temas; sensibilização; rotina de trabalho das marisqueiras; curso de boas práticas no beneficiamento de mariscos; e roda de conversa. As metodologias incluíram exposição dialogada, dinâmica de grupos, oficinas, teatro, uso de imagens, atividades dirigidas e distribuição de materiais didáticos. Ao final, solicitou-se a avaliação dos participantes quanto a distintos itens. Em geral, registrou-se satisfação do público-alvo, para a maioria dos indicadores, o que pode relacionar-se tanto à utilização de recursos audiovisuais e estratégias que permitiram troca de experiências, quanto ao reconhecimento da importância da formação. A experiência demonstra o potencial de desenvolvimento de atividades educativas junto a comunidades pesqueiras, com resultados que contribuem para o fortalecimento de cadeias produtivas locais, com promoção da segurança alimentar e da saúde do trabalhador.

Palavras-chave Pesca artesanal, Frutos do mar, Educação em saúde, Treinamento, Saúde do trabalhador, Segurança alimentar 


\section{Introdução}

A mariscagem compreende uma categoria de pesca artesanal muito peculiar no Brasil, em especial nas regiões litorâneas e ribeirinhas, sendo exercida, sobretudo, por mulheres - marisqueiras ou mariscadeiras, que desenvolvem a atividade tanto para consumo próprio quanto para venda $\mathrm{d}^{1,2}$.

Em São Francisco do Conde (BA), apesar da principal atividade econômica ser o processamento e o refino de petróleo, o que confere ao município o maior valor de Produto Interno Bruto per capita ${ }^{3}$ brasileiro, a mariscagem compreende importante estratégia de subsistência da população, que sofre com o agravamento das desigualdades sociais, enfrentando problemas associados à pobreza, à falta de infraestrutura sanitária e ao analfabetismo ${ }^{4}$.

Em todo o litoral baiano, assim como em São Francisco do Conde, os mariscos exercem forte influência na culinária, preservando a cultura alimentar local ${ }^{5}$. Nesse município, a mariscagem é praticada na sede municipal e em várias comunidades pesqueiras e se volta à captura de camarão, sururu, ostra, siri, mapé e caranguejo, que, em geral, são processados nas residências das marisqueiras e comercializados na localidade e em cidades circunvizinhas ${ }^{6,7}$.

Dado que algumas comunidades pesqueiras do município não contam com sistema público de abastecimento de água, esgoto e de coleta de lixo $^{7}$ e o fato do beneficiamento de mariscos tradicionalmente ser realizado em ambiente doméstico, há um contexto que concorre para a contaminação do pescado, resultando na obtenção de produtos com perfil microbiológico e físico-químico não conforme com os padrões nacionais vigentes ${ }^{8}$.

Nesse cenário, a busca pela qualidade dos alimentos passou a constituir tema de grande preocupação, posto que a inocuidade dos produtos obtidos encontra-se condicionada às condições estruturais de processo disponíveis nas comunidades e ao modo de atuação dos manipuladores de alimentos que, dentro de uma terminologia, compreende todas as pessoas que preparam, distribuem e/ou vendem alimentos ${ }^{9,10}$.

Considerando a qualidade do alimento como o resultado de um conjunto de condições e cuidados compreendidos em toda a cadeia produtiva, desde a obtenção da matéria-prima até a sua utilização ${ }^{10}$, pontua-se a necessidade de que princípios de higiene pessoal, de alimentos e do ambiente sejam estabelecidos, reforçados e monitorados, sendo essencial a realização de atividades de educação e de formação continuada, com vistas ao alcance de soluções às limitações higiênico-sanitárias existentes ${ }^{9-11}$.

Ao mesmo tempo, nessas comunidades, a atividade na mariscagem tem sido descrita como um trabalho precário, associado com a ocorrência de doenças relacionadas ao trabalho, com registro de elevados índices de problemas de coluna e ósteo-articulares, sobretudo nos membros superiores $^{12,13}$.

Assim, observando-se as condições descritas para o trabalho na produção de pescado beneficiado nas comunidades de São Francisco do Conde e a necessidade de contribuir para a segurança de alimentos e para a saúde ocupacional na pesca, este estudo tem por propósito descrever uma experiência de formação para marisqueiras, conduzida junto à comunidade pesqueira de Ilha do Paty, em um contexto de ações para a promoção da saúde e da segurança alimentar.

\section{Métodos}

Realizou-se estudo de intervenção, junto a marisqueiras da comunidade de Ilha do Paty, São Francisco do Conde, Brasil, no âmbito do projeto "A cadeia produtiva de pescados em São Francisco do Conde-BA: do barco à comercialização, na perspectiva da promoção da segurança alimentar". O trabalho foi conduzido entre outubro de 2011 e julho de 2012.

A Ilha do Paty é uma pequena comunidade pesqueira, com 152 habitantes, localizada a aproximadamente $70 \mathrm{Km}$ de Salvador, capital do es$\operatorname{tado}^{14}$. É dotada de áreas de vegetação pouco densa, cobrindo parcialmente a área do bosque e a proximidade de manguezais, nos quais a mariscagem é uma das principais atividades de subsistência ${ }^{13}$. A seleção da Ilha como locus do estudo resultou do fato de que entre as comunidades incluídas no estudo maior, ter-se encontrado condições propícias ao trabalho de intervenção: liderança comunitária com postura pró-ativa; boa receptividade da equipe de pesquisa pela comunidade; disponibilidade de local dotado de instalações para realização das atividades e público-alvo predominante de marisqueiras.

As atividades formativas foram planejadas pela equipe de pesquisa, com a participação da comunidade e compreenderam o desenvolvimento de cinco etapas: 1) sondagem de temas de interesse pela comunidade, com uso de questionário semiestruturado, visando fazer um 
levantamento dos temas com maior demanda; 2) sensibilização, por meio de palestras e atividades interativas, com objetivo de despertar a comunidade para a importância da qualidade e da segurança do pescado, destacadamente orientada para o seu beneficiamento, e alertar sobre cuidados para promoção da saúde do trabalhador; 3) acompanhamento da rotina de trabalho das marisqueiras, no qual foram registradas as condições de desenvolvimento do trabalho no mangue e de beneficiamento do pescado em domicílio, em diário de campo; 4) formação específica em Boas Práticas de Produção de alimentos, conduzida por meio de atividade educativa participativa, visando fomentar a manipulação segura de alimentos, nos diferentes estágios de beneficiamento; 5) roda de conversa com as marisqueiras, em atividade guiada por um roteiro de perguntas e discussão em grupo, sobre a efetividade do processo educativo conduzido, identificando elementos facilitadores e dificultadores da mudança de comportamento.

De modo a conhecer a percepção dos participantes, quanto às metodologias de formação utilizadas, ao final das atividades de sensibilização (etapa 2) e da formação específica em Boas Práticas (etapa 4), solicitou-se aos participantes o preenchimento de uma ficha de avaliação que considerava diferentes itens - explicação dos assuntos, recursos utilizados, ritmo das atividades, esclarecimentos de dúvidas e aprendizagem individual - e questões de opinião sobre os eventos e as sugestões para atividades futuras. Na avaliação dos itens foi utilizada uma escala estruturada ${ }^{15}$, contemplando cinco categorias de resposta: péssimo, ruim, regular, bom e ótimo. Para tratamento das respostas em escala, as categorias foram convertidas em valores numéricos, escala de um a cinco, e calculada a média aritmética de cada indicador; para as demais questões verificou-se a frequência de respostas.

Em todas as etapas do estudo, excetuando-se a sondagem, foram feitos registros fotográficos. Na roda de conversa, para fins de registro dos depoimentos, foi feita a gravação da atividade e a transcrição dos discursos dos participantes.

Para a operacionalização das atividades planejadas, contou-se com uma equipe multidisciplinar, composta por docentes, graduandos e mestrandos, das áreas de Nutrição, Fisioterapia, Medicina Veterinária, Engenharia de Alimentos e Gastronomia, da Universidade Fede- ral da Bahia (UFBA) e da Universidade do Estado da Bahia (UNEB).

Como princípios norteadores para o desenvolvimento das atividades, foram considerados: a construção participativa do planejamento do trabalho, marcada por reuniões de consenso, com atenção às demandas dos indivíduos da comunidade; a adequação dos métodos de formação à baixa escolaridade registrada para os moradores da Ilha; e o estímulo aos participantes para a manifestação do seu conhecimento e práticas, de modo a aproveitar a própria experiência local como base para a construção do novo conhecimento, conforme preconiza a literatura específica da área ${ }^{9,16-18}$.

Entre as metodologias utilizadas na condução das atividades, constaram: exposição dialogada, com uso de projetor multimídia; dinâmica de grupos; roda de conversa; simulações práticas; teatro; exibição de fotos do trabalho da mariscagem e de vídeos diversos; atividades dirigidas em grupo e individual; e concurso de paródias. Em adição, foram elaborados também materiais didáticos de apoio. Como forma de reconhecimento, valorização e de incentivo pela participação das marisqueiras nas atividades, todas que tiveram $100 \%$ de assiduidade receberam um certificado e houve ainda o sorteio de pequenos brindes.

Em atendimento à Resolução 196/96, do Conselho Nacional de Saúde ${ }^{19}$, este estudo foi aprovado pelo Comitê de Ética em Pesquisa da Escola de Nutrição, da Universidade Federal da Bahia, sendo a participação voluntária no estudo confirmada por assinatura de Termo de Consentimento Livre e Esclarecido.

\section{Resultados e discussão}

$\mathrm{Na}$ etapa da sondagem, os temas de interesse demandados pelos pescadores e pelas marisqueiras da comunidade pesqueira incluíram: assuntos relacionados à pesca $(34,58 \%)$; conservação, higiene e manuseio do pescado (29,63\%); direitos e deveres dos pescadores e marisqueiras $(14,81 \%)$; artesanato com maris$\cos (11,11 \%)$; conscientização para uso do meio ambiente $(11,11 \%)$; comidas típicas e culinária local $(7,41 \%)$ e saúde do pescador $(2,47 \%)$.

A atividade de sensibilização, denominada "Trabalho de marisqueira: agregando valor, saúde e qualidade", foi realizada em um único dia, com duração de seis horas, e contou com 16 participantes. O conteúdo programático abor- 
dado incluiu: valorização do trabalho das marisqueiras; princípios de microbiologia de alimentos; características do pescado: composição e deterioração; conservação de pescado; higiene do manipulador de alimentos; Boas Práticas de Produção (BPP) no beneficiamento de mariscos; e saúde no trabalho, com enfoque em Lesões por Esforços Repetitivos (LER) e Distúrbios Osteomusculares Relacionados ao Trabalho (DORT).

Nessa atividade, considerando a necessidade de todo ser humano de ser notado pelos outros, tanto no ambiente familiar como no trabalho, foi incluído um momento para abordar a valorização profissional. Para essa construção, partiu-se do pressuposto de que a valorização é algo que acontece de dentro para fora, ou seja, deve partir da própria pessoa que deseja ser reconhecida ${ }^{20}$.

Em adição, o conteúdo de microbiologia, foi intencionalmente introduzido, uma vez que, pelo diagnóstico de segurança de alimentos do projeto maior, de 18 amostras de mariscos (siri, sururu e ostra) obtidas na comunidade, oito $(44,45 \%)$ estavam impróprias para o consumo - pelo não atendimento de padrões microbiológicos, como estafilococos coagulase positiva e coliformes termotolerantes ${ }^{12}$. Assim, fazia-se necessário compreender os micro-organismos pesquisados e o seu significado nos resultados encontrados, o que serviu para despertar a comunidade sobre riscos sanitários e responsabilidade com a saúde pública, na produção de alimentos.

Adensando a perspectiva da segurança de alimentos, salienta-se o conteúdo desenvolvido sobre a qualidade do pescado, tema que, em uma abordagem mais ampla, incluiu aspectos sensoriais, como aparência e outras características de frescor, procedimentos de conservação e para controle de contaminações e alterações químicas, bem como a relação entre a qualidade do pescado e ambiente de pesca ${ }^{21,22 .}$

No âmbito da saúde do trabalhador, foi destaque a discussão relativa aos impactos da mariscagem sobre a saúde, posto que muitas marisqueiras relataram muitas dores, sobretudo em algumas partes do corpo, como mãos, braços, pescoço, ombros e coluna. Assim, visando aliviar as dores relacionadas à atividade laboral, foram conduzidas orientações sobre diversos exercícios de alongamento, despertando-as para os cuidados com o corpo, na promoção da qualidade de vida dessas trabalhadoras.
Como desdobramento do quadro de baixa qualidade dos pescados beneficiados na comunidade, bem como dos problemas de saúde evidenciados durante a sensibilização, verificou-se a necessidade de acompanhar e vivenciar a rotina de trabalho das marisqueiras, com o intuito de levantar informações específicas relativas à realidade de trabalho local e de buscar soluções viáveis para as dificuldades identificadas.

Assim, com a realização do acompanhamento "Marisqueira por um dia", foi possível registrar as formas de trabalho no mangue e nas residências, observando-se vestimenta, locais e instrumentos de trabalho, espécies capturadas, etapas de manipulação e procedimentos adotados no beneficiamento dos produtos. Nesse sentido, conforme orienta Freire ${ }^{16}$, buscou-se uma melhor aproximação da realidade dos sujeitos, em uma tentativa de maior conhecimento e compreensão do outro, no contexto social que o circunda.

Os resultados dessa atividade evidenciaram as dificuldades operacionais referentes ao desenvolvimento do trabalho, desde o deslocamento para as áreas de captura - de canoa a remo ou a pé, o esforço para movimentação no solo do mangue, o desgaste físico para captura e no uso dos apetrechos de pesca (machado e facão), a ausência de equipamentos de proteção individual (luvas, botas, chapéu, protetor solar, dentre outros), os riscos de acidentes de trabalho (quedas, cortes), a sobrecarga para transporte dos mariscos capturados (Figura 1) e a grande demanda

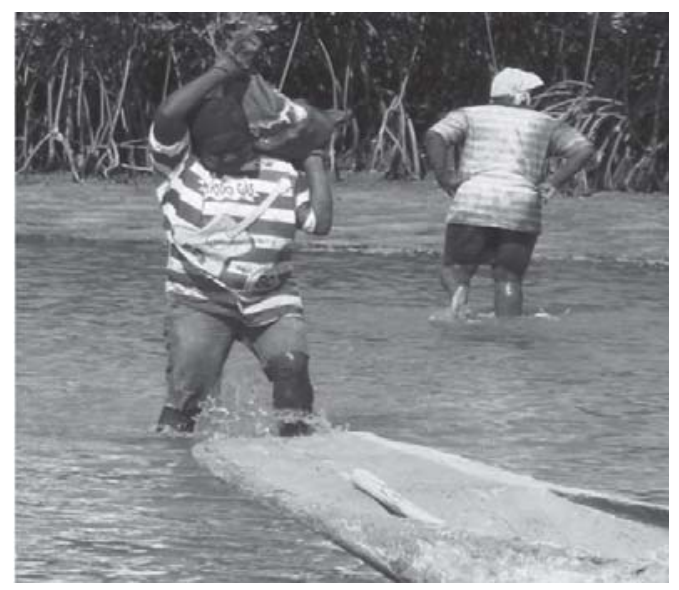

Figura 1. Sobrecarga física no transporte de mariscos capturados, na mariscagem. Ilha do Paty, Brasil, 2012. 
do trabalho dos membros superiores, na etapa de beneficiamento.

De acordo com pesquisa reportada pelo Centro Estadual de Referência em Saúde do Trabalhador/Secretaria de Saúde do Estado da Bahia $^{23}$, as marisqueiras compreendem trabalhadoras expostas a vários riscos, principalmente os ergonômicos, em virtude de posturas inadequadas, levantamento de peso e movimentos repetitivos. Do ponto de vista ergonômico, há uma sobrecarga muscular no pescoço, no dorso, nos ombros, nos membros superiores e na região lombar, além do excesso rítmico centrado no punho nas atividades repetidas $^{24}$. Em estudo realizado na Noruega, em Tromsø, com 1.767 funcionários, de 118 fábricas de processamento de frutos do mar, constatou que as partes/regiões do corpo dos trabalhadores com maior prevalência de dor foram o pescoço/ombro, braços/mãos e costas, com índices de $74 \%, 73 \%$ e $49 \%$, respectivamente ${ }^{25}$.

Conforme evidenciado nas residências da Ilha do Paty, a maior parte das marisqueiras beneficiava o pescado de forma imprópria, com utensílios improvisados - embalagens tipo latas e baldes, da área de construção civil e de alimentos, e ainda em bacias plásticas ou de alumínio, muito desgastadas. $\mathrm{O}$ beneficiamento ocorria em áreas abertas, em frente ou no quintal da própria residência e em locais improvisados, em cima de sacos plásticos (ráfia), no chão (Figura 2), ou em mesa de madeira, na presença de animais de estimação, demonstrando o desconhecimento das Boas Práticas de Manipulação.

De acordo com investigação conduzida por Argôlo et al. ${ }^{12}$, junto a 18 marisqueiras do município, todas beneficiavam os mariscos em

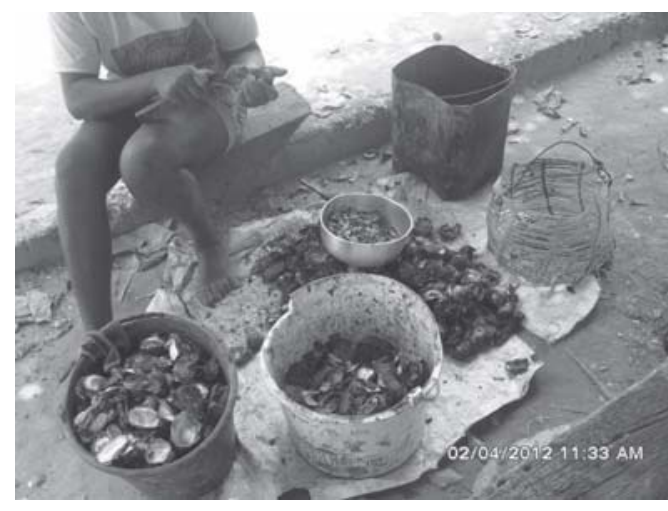

Figura 2. Beneficiamento de pescado por marisqueira. Ilha do Paty, Brasil, 2012. bacias dispostas sobre o chão, no próprio domicílio, alguns deles com estrutura bastante precária - em 33,3\% dos casos não havia água tratada. Em nenhum dos casos, as marisqueiras declararam ter recebido qualquer orientação para o trabalho com o pescado e $94,4 \%$, muitas vezes, vendiam todos os produtos beneficiados. Segundo a autora, os mariscos ficavam expostos à temperatura ambiente, por três a cinco horas, até que terminasse o beneficiamento de todo o pescado capturado, em função do volume da captura e da disponibilidade de auxiliares no serviço.

Nesse contexto, investigações realizadas no Nordeste brasileiro também têm identificado precariedade no ambiente de processamento de mariscos, em outras comunidades. Nishida et al. ${ }^{26}$, ao estudar catadores de mariscos em manguezais paraibanos, descrevem situação socioeconômica difícil e a inexistência de infraestrutura básica abastecimento de água encanada, sistemas de saneamento e de coleta de lixo - contribuindo para que os próprios catadores despejassem os dejetos e o lixo nas proximidades das comunidades, comprometendo a qualidade ambiental e o meio de vida. Nesse estudo, os autores relatam condições sanitárias inadequadas: cerca de 60,0\% das casas dos catadores de mariscos não possuíam banheiro, $46,7 \%$ não tinham sanitário, os dejetos, assim como o lixo, em $86,6 \%$ e $40,0 \%$ dos casos, eram lançados diretamente na maré.

Essa realidade também foi descrita por Bernardo et al. ${ }^{27}$, em estudo na Ilha de Deus, Recife (PE), onde evidenciaram condições higiênico-sanitárias inadequadas durante o processamento da carne de sururu e de outros mariscos, sobretudo em relação às instalações físicas, ao ambiente de manipulação - que acontecia a céu aberto - e à inexistência de rede de esgoto, com escoamento livre, diretamente no ambiente.

Considerando a natureza eminentemente prática da atividade "Marisqueira por um dia", foi possível a identificação dos pontos de interesse a serem abordados na implantação do curso de Boas Práticas de Produção de alimentos e na orientação das atividades a serem planejadas no âmbito da saúde do trabalhador.

O curso, denominado "Boas Práticas de manipulação: promovendo o trabalho das marisqueiras", foi realizado em duas tardes consecutivas, com 8 horas de duração, e teve como tema principal a manipulação segura, nos diferentes estágios do beneficiamento dos mariscos. O curso contou com a participação de 27 marisqueiras e os temas trabalhados compreenderam: Boas 
Práticas de manipulação de alimentos, qualidade da água, higiene pessoal, higiene dos utensílios e do ambiente, cuidados na captura, manipulação e preparação dos mariscos e aspectos de saúde do trabalhador e o uso de equipamentos de proteção individual (EPI). Como material didático de apoio, foram distribuídos: a Cartilha da marisqueira elaborada e atualizada pelo grupo de pesquisa - com conteúdo abordando tópicos como higiene pessoal, higiene na manipulação de alimentos, com utensílios e o ambiente de trabalho e controle de pragas, dentro do princípio das cinco chaves para a segurança de alimentos ${ }^{28}$; a Cartilha sobre LER e DORT para marisqueiras, contemplando seus conceitos, sintomas, causas e métodos para prevenção, e exercícios para alongamento e prevenção; e o Guia para higienização de caixas d'água - com um "passo a passo" para limpeza da caixa da água.

Nessa atividade, com base no fluxo de operações identificado na etapa anterior, foi possível uma construção participativa e detalhada do beneficiamento dos mariscos, com foco para os cuidados de higiene e conservação a serem adotados, com vistas à promoção da segurança dos produtos. Durante o desenvolvimento do conteúdo programático, a inserção de atividades lúdicas, como o teatro, as simulações de práticas de higiene, o uso de fotos da realidade local e os trabalhos em grupo contribuíram para reforçar a apropriação do conhecimento dos temas abordados. Considerando o público adulto, a adoção de maior número de técnicas de ensino (sensibilização, áudio, visual, prático) visava atingir uma aprendizagem mais eficiente ${ }^{29}$.

Segundo Tatagiba ${ }^{30}$, que realizou estudo com um grupo de educadores, no Rio de Janeiro (RJ), as dinâmicas do grupo favorecem a troca de experiências e permitem o processo de construção do saber. Nesse contexto, a experiência do indivíduo não pode ser desprezada, a descoberta de um passa a fazer parte da experiência do outro e proporciona-se a troca de conhecimento a partir do que o grupo pode trazer, produzir e viver. Dessa forma, não é o instrutor que detém todo o conhecimento - o grupo é que auxilia na construção do saber, pela participação e pelo trabalho coletivo, na qual cada membro é estimulado a contribuir com considerações, reflexões e análises, abrindo espaço para ouvir o que o outro tem a dizer.

Para Ballestero-Alvarez ${ }^{31}$, as atividades lúdicas são excelentes para introduzir e/ou reforçar os conceitos microbiológicos, como perigos, alimentos seguros, Boas Práticas, e apresentam, geralmente, uma boa aceitação pelos participantes. Entre essas atividades, encontra-se o teatro, que constitui uma linguagem poderosa, com alto poder de síntese, rica de possibilidade estética, capaz de proporcionar impacto múltiplo e diversificado, além de promover a integração entre os participantes ${ }^{32}$.

Em relação ao uso de jogos, destaca-se o seu auxílio na construção de novas descobertas, no desenvolvimento e enriquecimento da personalidade e porque simboliza um instrumento pedagógico que permitem ao instrutor a condição de condutor, estimulador e avaliador da aprendizagem. Adicionalmente, o caráter de integração e interação contidas nas atividades lúdicas proporcionam a integração do conhecimento com ações práticas ${ }^{33}$.

Em relação ao uso de fotos, Recuero ${ }^{34}$ explicita a capacidade de captar um momento, uma realidade, em momento único, como testemunha ocular do fato. Ao mesmo tempo, proporciona comunicação, revela inúmeras possibilidades de interpretação, ainda que em momento "congelado", e motiva mudanças de pensamento e de comportamento.

O uso da ludicidade como recurso pedagógico, além de observar o seu valor educacional intrínseco, considera dois elementos que a caracterizam: o prazer e o esforço espontâneo. O prazer decorre da sua capacidade de absorver o indivíduo de forma intensa e total, criando um envolvimento emocional, o que encerra o forte teor motivacional da atividade. Ao mesmo tempo, as atividades lúdicas são excitantes e requerem um esforço voluntário, o que mobiliza para o desenvolvimento de esquemas mentais, estimulando o pensamento ${ }^{35,36}$.

Como resultado do concurso de paródias, um grupo de marisqueiras compôs uma canção, que integrava palavras-chave na perspectiva da segurança dos produtos e da saúde do trabalhador, conforme se transcreve a letra abaixo. Dada a criatividade da equipe, a apresentação da música foi posteriormente produzida sob a forma de vídeo.

\section{Trabalho de marisqueira - higiene e proteção}

(Marisqueira 1, Marisqueira 2 e Marisqueira 3)

Na Ilha do Paty, foi que começou, o curso de Boas Práticas de manipulação: promovendo o trabalho das marisqueiras para qualificar o nosso pescado. 
Quando vou mariscar levo os EPI, para me proteger dos acidentes e do sol. Quando chego em casa, faço a higiene, separo os utensílios para sanitizar. (refrão) Quando eu cato o meu pescado, eu ponho a touca, corto as minhas unhas

e lavo bem as mãos.

Para proteger das bactérias e dos micro-organismos

que são as Salmonelas.

(refrão)

Após a realização deste curso, para fins de verificação e orientação quanto aos procedimentos adotados no beneficiamento, em atividade prática, o que constituía uma demanda da própria comunidade, procedeu-se à consulta sobre a possibilidade de haver um acompanhamento do processamento nas residências. Apesar de muitas marisqueiras terem concordado inicialmente com esta proposta, quando da sua implementação, não houve boa adesão, o que limitou o treinamento idealizado.

Nesse sentido, embora não tenham sido explicitadas as razões da negação, conversas em campo com algumas marisqueiras, fizeram pensar sobre a necessidade de preservação da privacidade, a não revelação das condições de moradia e a não alteração da rotina doméstica.
A última etapa da pesquisa consistiu na Roda de Conversa na Mariscagem, realizada durante uma tarde e que contou com a participação de 12 marisqueiras. A oficina contemplou uma retomada do propósito das atividades formativas, o reforço às orientações em saúde do trabalhador e a roda de conversa, propriamente, com trabalho em grupo e resposta ao roteiro de perguntas, com socialização posterior, em um processo de escuta sensível à comunidade ${ }^{16}$.

No início, no intervalo e ao final da atividade, foram realizadas orientações quanto à ergonomia e postura para mariscagem, alguns exercícios de automassagem e atividades de alongamentos, individual e em grupo, pela equipe de fisioterapia, com objetivo de manter ou melhorar a flexibilidade do corpo, consideradas essenciais na prevenção de LER e DORT ${ }^{37}$.

Quanto à avaliação da sensibilização e do curso, feita pelos participantes, os resultados encontram-se sumariados na Figura 3. Como se verifica, para ambos os cursos, as notas de avaliação foram satisfatórias, com médias acima de quatro, e, para a maior parte dos itens avaliados, o curso apresentou desempenho superior à sensibilização, a exceção do item esclarecimento às dúvidas.

Quanto à explicação dos assuntos, a nota média passou de 4,56, na sensibilização, para 4,74 , no curso, o que faz depreender o bom nível de

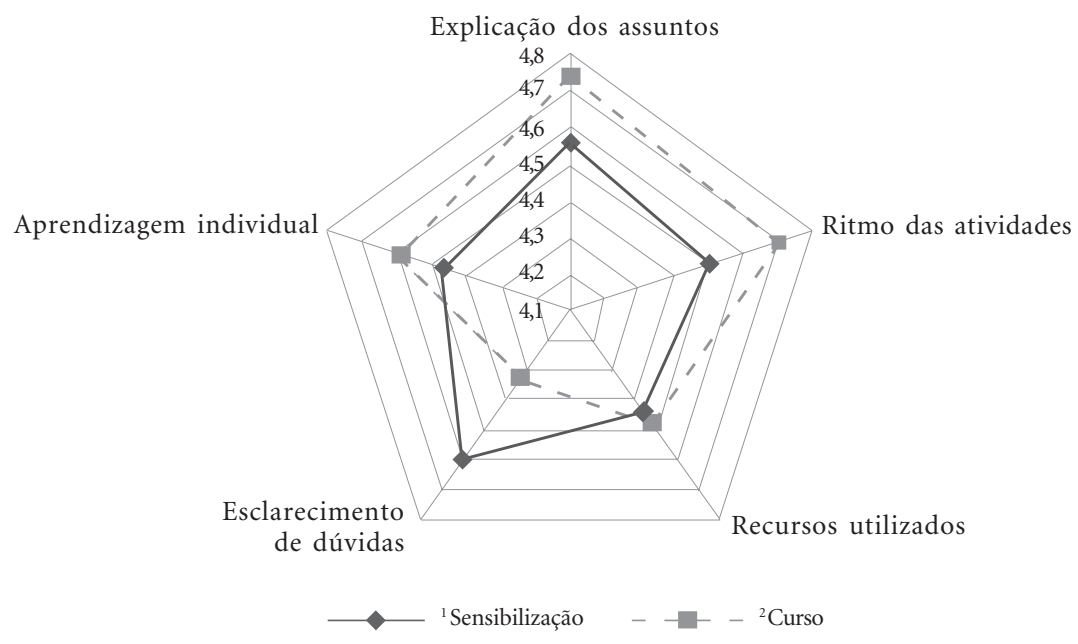

Figura 3. Média das notas para itens de avaliação das atividades de sensibilização e curso, conduzido junto a marisqueiras da Ilha do Paty, Brasil, 2012. 
comunicação e interação entre os instrutores da equipe e os participantes. No item ritmo das atividades, apesar das médias elevadas, $12,5 \%$ e $15,0 \%$ dos participantes da sensibilização e do curso, respectivamente, indicaram conceito regular (nota 3), o que aponta para o fato das atividades apresentarem intensidade ou densidade de conteúdo alta para o tempo planejado, limitando um espaço maior para apreensão e internalização dos temas apresentados.

Assim, para melhor aproveitamento dos participantes, este resultado sinaliza a necessidade de desenvolver um trabalho de formação mais compassado, com carga horária maior, compatível à ampla inclusão de indivíduos de menor escolaridade, oferecendo oportunidade para questionamentos, debates e outras formas de fixação, em que os participantes sejam mais ativos.

Em relação aos recursos utilizados, os resultados da etapa da sensibilização, média 4,44, e do curso, média 4,48, apresentaram pontuação próxima, posto que se conformavam da disponibilidade material da equipe e da reflexão sobre que estratégias contribuiriam de modo significativo à aprendizagem. Nesse sentido, embora não tenha sido viável, ressalta-se a importância de se trabalhar os conteúdos de forma prática, o que possibilitaria a apropriação do conhecimento em uma perspectiva do aprenderfazendo, no contexto da aprendizagem de um coletivo $^{38,39}$.

Quanto ao esclarecimento de dúvidas, a atividade de sensibilização obteve média 4,60, enquanto que para o curso foi 4,30. Possivelmente, esse resultado está relacionado à abordagem de conteúdo mais específico e técnico, durante o curso, focado nas Boas Práticas de manipulação de mariscos, com uso de termos específicos e maior quantidade de informações, o que dificultou, em parte, a compreensão do público-alvo. Esse resultado reforça a relevância da realização de atividades em educação continuada, o que oportuniza maior familiarização com os termos e procedimentos associados às Boas Práticas, uma vez que a acumulação de conhecimento per se é processual ${ }^{40}$, sendo as informações gradativamente assimiladas pelo público-alvo.

No que se refere ao aspecto de aprendizagem individual, houve uma discreta melhoria nos resultados da avaliação - de 4,47 na sensibilização para 4,59 no curso. Esse resultado mostra-se positivo, apesar das limitações de ritmo explicitadas, e expõe um aspecto importante que se refere à apropriação do saber, por meio de uma superação constante e a possibilidade de ampliação do conhecimento quando há algum conhecimento pregresso sobre o assunto ${ }^{37}$ - neste caso, considera-se o conhecimento vulgar e aquele decorrente dos meios de comunicação que as marisqueiras já acumulavam. Adicionalmente, este aspecto reforça o entendimento de que informações conhecidas ajudam a fixar o conteúdo novo e permitem relacionar as novas informações com o conhecimento trazido.

Freire ${ }^{16}$ afirma que educar exige tempo, participação, escuta e respeito ao aprendente. Exige implicação mútua e a consciência da existência de saberes nem maiores, nem melhores, apenas diferentes. O educar deve despertar a renovação constante da curiosidade, da criatividade, da busca de respostas, da autonomia. Para o educador, é imprescindível a consciência de também ser um aprendente - é preciso estudar e aprender a aprender.

Entre as sugestões apontadas pelas marisqueiras, com vistas ao aperfeiçoamento das atividades formativas, constaram: a necessidade de maior participação da comunidade no curso; maior tempo para realização das atividades, com espaço para responder aos questionamentos; e a solicitação do retorno da equipe de pesquisa à comunidade, com o compromisso de manter as atividades e discutir os resultados obtidos, de modo a orientar a melhoria da qualidade do pescado beneficiado e os cuidados com a saúde do trabalhador.

Por meio da roda de conversa, foi possível observar grande satisfação dos participantes em relação às atividades realizadas e a apreensão dos assuntos abordados, com mudanças no comportamento, conforme pode ser observado nas respostas abaixo:

É, já limpava a embarcação, mas passou a cuidar melhor na hora de botar, de tirar o marisco, tal: quando a gente vê que tem sujeira passa uma água e não coloca mais o marisco em cima da lama, bota o pescado, o marisco em cima do plástico. Grupo 1.

Reforçou na higiene durante a catação: lavar a mão depois de atender o telefone, ter um balde só pra os mariscos e lavar ele antes de usar. Hoje eu sei que não devo pegar qualquer balde pra mariscar. Isso aí eu aprendi muito que antes eu não fazia. Grupo 2.

... coisas que não fazíamos, passamos a fazer: assim, usar a touca que a gente não usava. Muitas vezes, quando chegava da mariscagem não tomava banho, catava logo o marisco. Hoje, a gente já faz diferente, por exemplo, já bota uma touca ou lenço no cabelo para não cair cabelo, lava a mão com 
frequência, a gente cobre o marisco direitinho. Grupo 3.

Observar se os equipamentos de proteção individual [EPI] e as ferramentas [apetrechos de pesca] estão em bom estado para mariscar. Grupo 3.

Na pergunta referente à dificuldade para fazer mudanças no modo de trabalho, após o curso, o que foi mais fácil e o mais difícil, um dos grupos sintetizou ambos, a dificuldade e a mudança:

Sim [foi difícil]. Mais fácil: continuar com higiene. Mais difícil: lavar o pescado antes de cozinhar, principalmente a dona ostra, porque como a gente pegava dois, três ou quatro baldes de ostra para lavar era mais difícil ... é o trabalho de lavar a ostra, porque a ostra é um marisco muito cortante. Para você lavar ela antes de cozinhar, está correndo o risco de se cortar, mas também era só a ostra que não lavava. Os outros, os demais, a gente lavava; ninguém aqui diga que lavava a ostra que não lavava. Se dizer isso vai tá mentindo. Mas, hoje, a gente já passa uma água e bota para cozinhar. Grupo 2

Como sugestões, para o aprimoramento de atividades futuras e o fortalecimento da cadeia produtiva local, a partir da roda de conversa, foram citadas: a necessidade de conscientização dos companheiros da comunidade; a disponibilidade de equipamentos utilizados para beneficiamento, como exemplo um fogão, de modo a não precisarem cozinhar à lenha; um mercado certo para o escoamento e a venda dos produtos beneficiados; palestras sobre o cooperativismo, para solucionar demandas da comunidade; serviços de fisioterapia para atendimento às marisqueiras; e informações sobre a alimentação - o que comer para trabalhar no mangue, como melhorar a alimentação e cuidados dietéticos para doenças crônicas não transmissíveis como diabetes e hipertensão, dentre outras.

Pelo conjunto de avaliações feitas, as atividades formativas tiveram a aprovação pelo público-alvo, o que pode ser explicado pelos recursos utilizados e pelas estratégias metodológicas adotadas, que permitiram a integração entre a equipe de instrutores e a comunidade, a oportunidade de troca de experiências entre todos, bem como pela identificação e reconhecimento da relevância da atividade pelas marisqueiras, uma vez que as temáticas abordadas constituíam interesse e realidade delas.

Assumindo como princípio que ensinar não é transferir conhecimento, mas criar as possibilidades para a própria produção ou construção do conhecimento ${ }^{38}$, avalia-se que foi possível a implantação de um processo educativo, visando uma transformação prática na comunidade pesqueira, em uma vertente de respeito às pessoas $\mathrm{e}$ de reconhecimento das dificuldades e limitações, possíveis de serem superadas.

\section{Considerações finais}

A experiência evidencia o potencial do desenvolvimento de atividades educativas junto a comunidades pesqueiras, no que tange ao aprimoramento do beneficiamento dos mariscos, à promoção da segurança alimentar e à saúde do trabalhador, em um processo de construção coletiva e de parceria com a comunidade.

Entre as estratégias metodológicas utilizadas, destaca-se o uso de métodos interativos, as dinâmicas e o emprego de imagens, em processos de construção do conhecimento, tendo como base a realidade local e a contribuição dos participantes para apreensão do saber.

Ainda que os participantes tenham manifestado, de modo geral, satisfação na avaliação das atividades conduzidas, sinaliza-se a necessidade de melhoria do modelo de intervenção, quanto ao ritmo das atividades, e de inclusão de atividades práticas, buscando aumentar a eficácia da formação.

Pelo caráter formativo, sugere-se a continuidade do estudo, com vistas a mensurar a sua efetiva contribuição para a melhoria da segurança dos produtos e na qualidade de vida das pessoas envolvidas. Igualmente, dada a natureza da intervenção e a insuficiência de estudos nesse campo, considera-se a contribuição social e científica do trabalho e aponta-se para importância da amplificação e divulgação de experiências nessa linha. 


\section{Colaboradores}

GS Nóbrega, RCV Cardoso, DMN Furtunato, JAW Góes, TCB Ferreira, MDF Santos e SMG Santos participaram das atividades de formação e são responsáveis pela autoria e revisão final desse texto.

\section{Agradecimentos}

Agradecemos a Fundação de Amparo à Pesquisa do Estado da Bahia (FAPESB) pelo apoio financeiro, ao líder da comunidade pesqueira de Ilha do Paty, São Francisco de Conde- BA, Sr. Altamirando Amorim, pela receptividade e atenção com a equipe do projeto e às marisqueiras, que participaram das atividades formativas com empenho e dedicação.

\section{Referências}

1. Clauzet M, Ramires M, Barrela W. Pesca artesanal e conhecimento local de duas populações Caiçaras (enseada do Mar Virado e Barra do Uma) no litoral de São Paulo, Brasil. Multiciência: A Linguagem da Ciência 2005; 4:1-23.

2. Martins VLA, Pena PGL, Martins YD, Seixas JM, Gomes TMD, Goés HTS. Guia de orientações para identificações de LER/DORT em pescadores artesanais-marisqueiras. Salvador: Bahia Pesca; 2011.

3. Instituto Brasileiro de Geografia e Estatística (IBGE). Posição ocupada pelos 100 maiores municípios, em relação ao Produto Interno Bruto per capita e população, segundo os municípios e as respectivas Unidades da Federação do Produto interno bruto dos municípios 2004-2008. Rio de Janeiro: IBGE; 2008.

4. Germano PML, Germano MIS. Comércio varejista de pescado: qualidade higiênico-sanitária. In SilvaSouza AT, organizador. Sanidade de Organismos Aquáticos no Brasil. Maringá: Abrapoa; 2006. p. 369-385.

5. Valente D, Passos ADC. Avaliação higiênico-sanitária e físico-estrutural dos supermercados de uma cidade do Sudeste do Brasil. Rev Bras Epidemiol 2004; 7(1):37-42.

6. Secretaria de Educação da Prefeitura Municipal de São Francisco do Conde (BA). Caracterização geral do município de São Francisco do Conde. São Francisco do Conde: Secretaria de Educação da Prefeitura Municipal de São Francisco do Conde; 2009.

7. Centro de Estudos Socioambientais. Projeto Repescar. São Bento - Diagnóstico socioeconômico e ambiental [Relatório Técnico]. São Bento: Pangea; 2008.

8. Campos PN, Cardoso RCV. Pescados comercializados no mercado municipal de São Francisco do Conde - BA: retratando a qualidade microbiológica. In: XXX Seminário Estudantil de Pesquisa e Pós-Graduação; Salvador: Universidade Federal Bahia; 2011.

9. Germano PML, Germano MLS. Higiene e vigilância sanitária dos alimentos. São Paulo: Manole; 2011.

10. Organização Mundial da Saúde (OMS). Doenças de origem alimentar: enfoque para educação e saúde. São Paulo: Roca; 2006.

11. Oliveira MN, Brasil ALD, Taddei JAAC. Avaliação das condições higiênico-sanitárias das cozinhas de creches públicas e filantrópicas. Cien Saude Colet 2008; 13(3):1051-1060.

12. Argôlo SV, Vieira NC, Moura DCC, Campos PN, Cardoso RCV, Guimarães AG. Trabalho de marisqueira e qualidade de mariscos beneficiados: um estudo em comunidades de São Francisco do Conde - Bahia. V Simpósio de Controle de Qualidade do pescado; 2012; jun 19-21; Santos, Brasil. São Paulo: SIMCOPE; 2012.

13. Sá EP. A pesca, o pescador e a cadeia de distribuição do pescado: um estudo exploratório em comunidades de São Francisco do Conde-BA [dissertação]. Salvador: Universidade Federal da Bahia; 2011. 
14. Carvalho EB, organizador. Diagnóstico Sócio-econômico e Ambiental do Município de São Francisco do Conde- BA. Salvador; 2006.

15. Vieira S. Como elaborar questionários. São Paulo: Atlas; 2009.

16. Freire P. Pedagogia da autonomia: saberes necessários à prática educativa. São Paulo: Paz na Terra; 1996.

17. Pereira ALF. As tendências pedagógicas e a prática educativa nas ciências da saúde. Cad Saude Publ 2003; 19(5):1527-1534.

18. Juzwiak CR, Castro PM, Batista SHSS. A experiência da Oficina Permanente de Educação Alimentar e em Saúde (OPEAS): formação de profissionais para a promoção da alimentação saudável nas escolas. Cien Saude Colet 2013; 18(4):1009-1018.

19. Brasil. Resolução nº 196 de 10 de outubro de 1996. Dispõe sobre as Diretrizes e Normas Regulamentadoras de Pesquisas Envolvendo Seres Humanos. Diário Oficial da União 1996; 16 out.

20. Leite CL. Desenvolvimento e Impacto de Ações de Intervenção para Apoio à Produção de Alimentos Seguros: Estudo em Escolas Estaduais Atendidas pelo Programa Nacional de Alimentação Escolar em Salvador-BA [dissertação]. Salvador: Universidade Federal da Bahia; 2008.

21. Huss HH. Garantia da qualidade dos produtos da pesca. Roma: FAO; 1998.

22. Moura JF, Cardozo M, Belo MSSP, Hacon S, Siciliano S. A interface da saúde pública com a saúde dos oceanos: produção de doenças, impactos socioeconômicos e relações benéficas. Cien Saude Colet 2011; 16(8):3469-3480.

23. Centro Estadual de Referência em Saúde do Trabalhador (Cesat). Informativo. Bahia: Cesat; 2010.

24. Pena PGL, Freitas MCS, Cardim A. Trabalho artesanal, cadências infernais e lesões por esforços repetitivos: estudo de caso em uma comunidade de mariscadeiras na Ilha de Maré, Bahia. Cien Saude Colet 2011; 16(8):3383-3392.

25. Aasmoe L, Bang B, Egeness C, Løchen M. Musculoskeletal symptoms among seafood production workers in North Norway. Occup Med 2008; 58(1):6470.

26. Nishida AK, Nordi N, Alves RRN. Aspectos socioeconômicos dos catadores de moluscos do litoral paraibano, Nordeste do Brasil. Rev de Biologia e Ciências da Terra 2008; 8(1):207-215.

27. Bernardo SJ, Maciel MIS, Silva APG. Avaliação dos aspectos higiênico-sanitários no processamento de moluscos na comunidade de pescadores (as) artesanais da Ilha de Deus, Recife - PE. XX Congresso Brasileiro de Economia Doméstica; 2009; 14-19 set; Fortaleza, Brasil. Ceará: CBED; 2009.
28. Organização Mundial de Saúde (OMS). Cinco chaves para uma alimentação mais segura. Departamento de Segurança Alimentar, Zoonoses e Doenças de Origem Alimentar. Brasília: OMS; 2006.

29. Abdussalam M, Kaferstein FK. Safety of street foods. WLD Hlth Forum 1993; 14(2):191-194.

30. Tatagiba MC. Vivendo e aprendendo com grupos: uma metodologia construtivista de dinâmica de grupo. Rio de Janeiro: DP \& A Editora; 2002.

31. Ballestero-Alvarez ME. Mutadis mutandis: dinâmicas de grupo para o desenvolvimento humano. Campinas: Papirus; 2001.

32. Carvalho AC. Teatro-Treinamento. 2008. [Internet]. [acessado 2013 ago 06]. Disponível em: http: www. centurione.com.br

33. Chaguri JP. O uso de atividades lúdicas no processo de ensino/aprendizagem de espanhol como língua estrangeira para aprendizes brasileiros [monografia]. São Paulo: Unicamp; 2006.

34. Recuero CL. Fotografia: contraponto entre a narração da realidade e a sua compreensão. Revista Teórica del Departamento de Ciencias de la Comunicación 2006; 3(2):1-10.

35. Teixeira CEJ. A Ludicidade na Escola. São Paulo: Loyola; 1995.

36. Maluf ACM. Brincadeiras para sala de aula. Rio de Janeiro: Vozes; 2007.

37. Barbosa LG. Fisioterapia preventiva nos distúrbios osteomusculares relacionados ao trabalho - DORT: fisioterapia do trabalho aplicada. Rio de Janeiro: Guanabara Koogan; 2009.

38. Freire P. Educação e mudança. São Paulo: Paz e Terra; 2001.

39. Barbier R. A pesquisa-ação. Brasília: Plano; 2002.

40. Ricardo EC. Discussão acerca do ensino por competências: problemas e alternativas. Cadernos de Pesquisa 2010; 40(140):605-628.

Artigo apresentado em 09/04/2013

Aprovado em 03/09/2013

Versão final apresentada em 14/09/2013 